\title{
Civilian gunshot wounds to the head: a case report, clinical management, and literature review
}

\author{
Haoyi Qi ${ }^{1}$ and Kunzheng $\mathrm{Li}^{2^{*}}$
}

\begin{abstract}
Background: Civilian gunshot wounds to the head refer to brain injury caused by projectiles such as gun projectiles and various fragments generated by explosives in a power launch or explosion. Gunshot wounds to the head are the deadliest of all gun injuries. According to literature statistics, the survival rate of patients with gunshot wounds to the head is only $9 \%$. Due to the strict management of various types of firearms, they rarely occur, so the injury mechanism, injury and trauma analysis, clinical management, and surgical standards are almost entirely based on military experience, and there are few related reports, especially of the head, in which an individual suffered a fatal blow more than once in a short time. We report a case with a return to almost complete recovery despite the patient suffering two gunshot injuries to the head in a short period of time.

Case presentations: We present a case of a 53-year-old man who suffered two gunshot injuries to the head under unknown circumstances. On initial presentation, the patient had a Glasgow Coma Scale score of 6, was unable to communicate, and had loss of consciousness. The first bullet penetrated the right frontal area and finally reached the right occipital lobe. When the patient reflexively shielded his head with his hand, the second bullet passed through the patient's right palm bone, entered the right frontotemporal area, and came to rest deep in the lateral sulcus. The patient had a cerebral hernia when he was admitted to the hospital and immediately entered the operating room for rescue after a computed tomography scan. After two foreign body removals and skull repair, the patient recovered completely.

Conclusions: Gunshot wounds to the head have a high mortality rate and usually require aggressive management. Evaluation of most gunshot injuries requires extremely fast imaging examination upon arrival at the hospital, followed by proactive treatment against infection, seizure, and increased intracranial pressure. Surgical intervention is usually necessary, and its key points include the timing, method, and scope of the operation.
\end{abstract}

Keywords: Gunshot wound, Head trauma, Penetrating brain injury, Traumatic brain injury

\footnotetext{
*Correspondence: likunzheng6810@163.com

${ }^{2}$ The Affiliated Hospital of Qinghai University, No. 29 Tongren Road, Xining 810000, Qinghai Province, China

Full list of author information is available at the end of the article
}

(c) The Author(s). 2021 Open Access This article is licensed under a Creative Commons Attribution 4.0 International License, which permits use, sharing, adaptation, distribution and reproduction in any medium or format, as long as you give appropriate credit to the original author(s) and the source, provide a link to the Creative Commons licence, and indicate if changes were made. The images or other third party material in this article are included in the article's Creative Commons licence, unless indicated otherwise in a credit line to the material. If material is not included in the article's Creative Commons licence and your intended use is not permitted by statutory regulation or exceeds the permitted use, you will need to obtain permission directly from the copyright holder. To view a copy of this licence, visit http://creativecommons.org/licenses/by/4.0/ The Creative Commons Public Domain Dedication waiver (http://creativecommons.org/publicdomain/zero/1.0/) applies to the data made available in this article, unless otherwise stated in a credit line to the data. 


\section{Background}

The surgical management of gunshot wounds to the head $(\mathrm{GWH})$ is still a challenging issue in neurosurgery [1]. Even after experience acquired during the two World Wars and multiple local wars, the surgical management of such patients still needs further discussion because mortality and morbidity remain high despite technological improvements in the last decades $[1,2]$. Neurosurgeons vary considerably in their approaches to GWH. Studies have shown that the age of the patient, a high preoperative Glasgow Coma Scale (GCS) score, lack of pupil abnormalities, and absence of intracerebral hematoma are predictors of a good prognosis [1].

The largest retrospective studies to date have shown that penetrating GWH are very often fatal even with appropriate medical and surgical treatment, with $71 \%$ of patients dying at the scene, 66-90\% of those dying before reaching a hospital, and up to a $51 \%$ survival rate among those reaching the hospital alive [3-5]. We highlight the current management guidelines, prognostic factors, and survival outcomes in patients with penetrating $\mathrm{GWH}$. We report a case that is unique due to the successful outcome and return to almost complete recovery despite two gunshots to the head and a low GCS score. We defined the almost complete recovery as the ability to complete simple, repetitive farming activities by himself without the care of his family.

\section{Case presentation}

A 53-year-old male with two GWH to his right cerebral hemisphere presented with a GCS score of 6 to the hospital. According to the emergency physician's report, the patient was taken to the hospital about $3 \mathrm{~h}$ after the injury. The patient was on the way to the hospital with a fixed right pupil, so he was given mannitol timely in the ambulance. We speculated that the duration of brain herniation was at least $1 \mathrm{~h}$. He was hemodynamically stable and intubated, there were two adjacent bullet holes in the patient's right frontal area, and no ballistic exit was seen. Neurological examination revealed that his right pupil was fixed and dilated, and his left pupil was $2.5-\mathrm{mm}$ wide and reactive. $\mathrm{He}$ was responsive to pain stimuli but not to verbal stimuli. A computed tomography (CT) scan of the head revealed a bullet trajectory with a right frontal comminuted fracture and bony and metallic fragments in the right frontal and right occipital lobes. There was also some brain tissue swelling with a midline shift to the left and subarachnoid hemorrhage (Fig. 1). Since the patient had a brain herniation at admission, he was immediately transferred to the operating room for debridement and decompressive
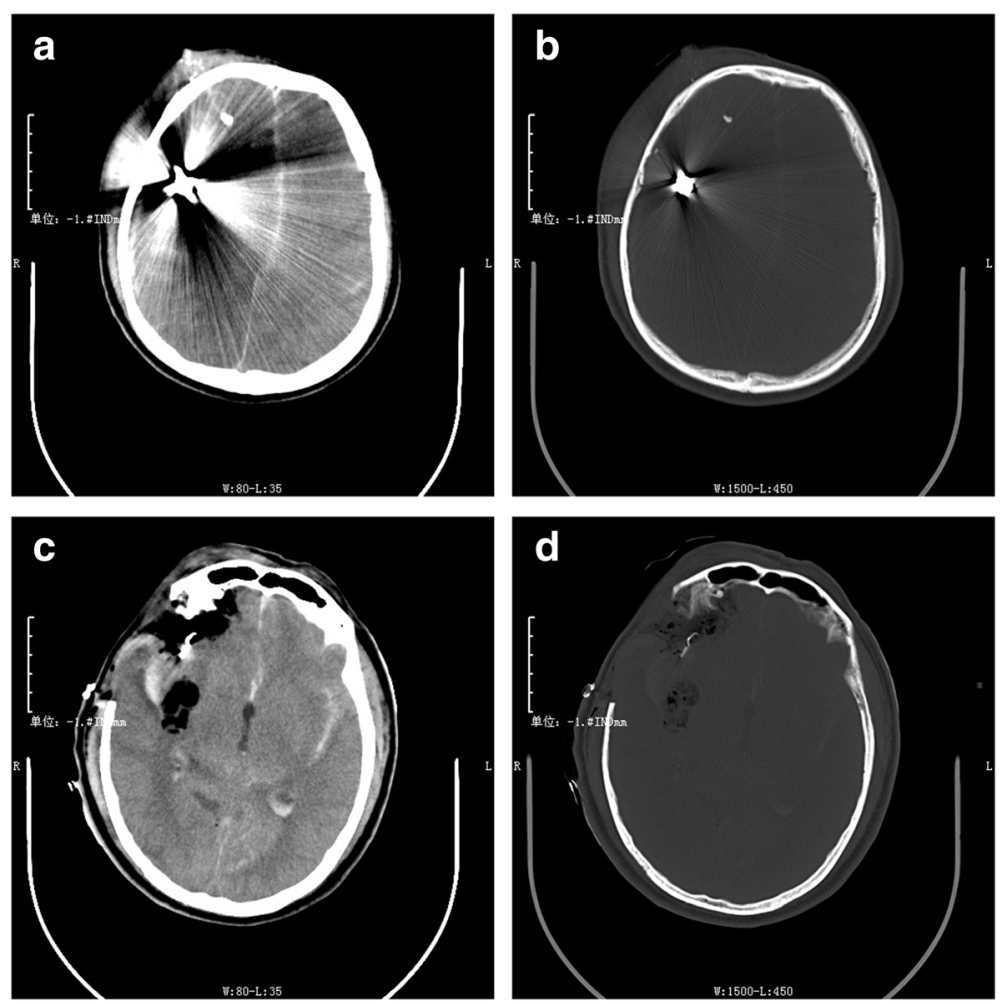

Fig. 1 Computed tomography (CT) upon admission. a Soft tissue windows and $\mathbf{b}$ bone windows, showing the metal artifacts from the bullet case. Postoperative CT on the same day in soft tissue windows $\mathbf{c}$, and bone windows $\mathbf{d}$ after decompressive craniectomy 

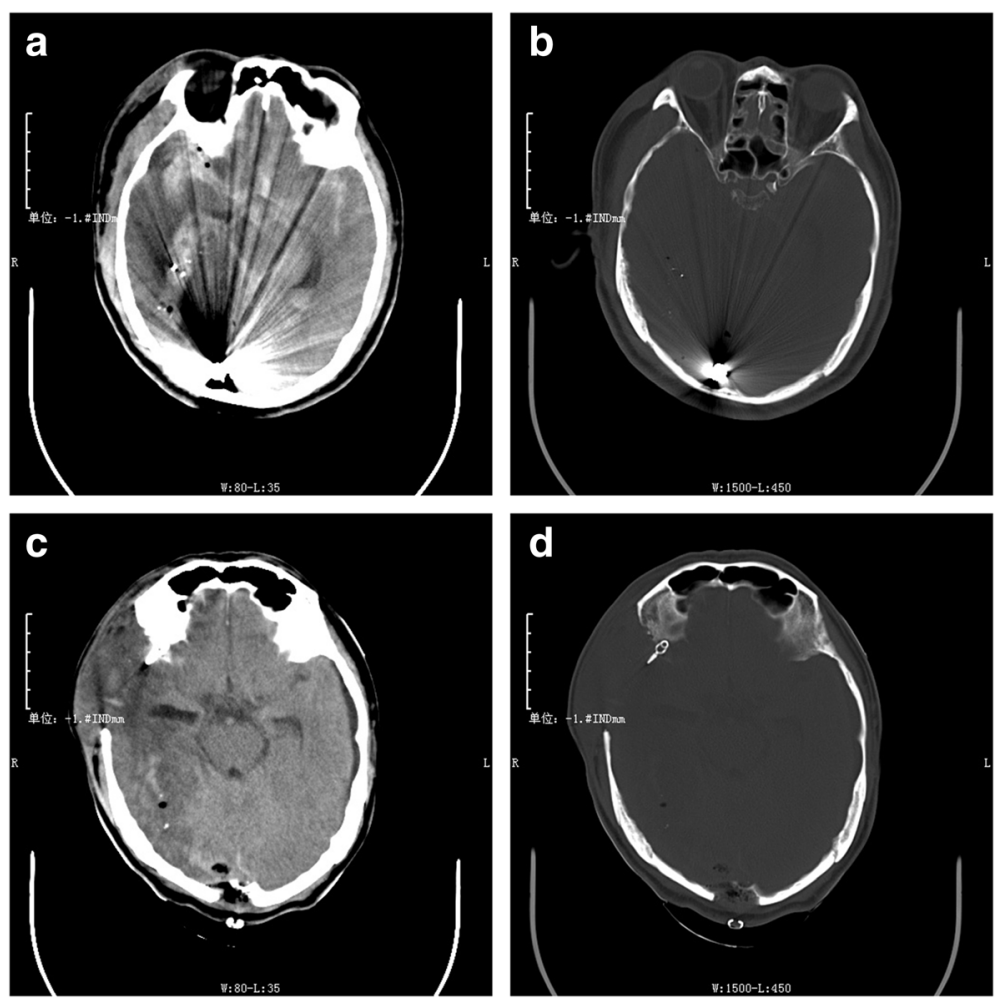

Fig. 2 Computed tomography (CT) upon admission. a Soft tissue windows and $\mathbf{b}$ bone windows, showing the bullet fragment in the occipital lobe. Postoperative CT scan in soft tissue windows $\mathbf{c}$ and bone windows $\mathbf{d}$ after the second operation, clearly showing the skull window accommodating some swelling

craniectomy after the first CT scan. Considering the specificity of the patient's intracranial hematoma location and foreign body location, we performed an extended pterional approach and decompressive craniectomy in time. We did not temporarily remove the foreign body in the occipital lobe but waited for the patient's vital signs to stabilize after the first operation and then evaluated whether it was suitable for removal or maintenance. The analysis of why this decision was taken is presented in detail in the surgical management section. The patient recovered well after the first operation with no infection or brain abscess development and underwent a second operation 2 weeks later to remove the foreign body in the occipital lobe (Fig. 2). He was discharged 7 days later. The patient visited the hospital for a re-examination 2 months after the injury, and hydrocephalus was found to have occurred. We performed skull repair 3 months after injury. The patient came in for a 6-month follow-up. During the subsequent follow-up, hydrocephalus did not continue to develop, and head CT yielded no new or concerning findings, so we did not perform additional clinical management (Fig. 3). The last telephone followup was performed a year after his injury. According to the patient's family members, the self-care ability of the patient was fair, and he could complete housework alone. There was no obvious cognitive impairment, but his personality had slightly changed. The main manifestation was that he did not like to communicate with others. He did not experience seizures or other neurological symptoms. The Wisconsin card sorting test was used to assess the patient's performance during the follow-up. The result was good. A series of noncognitive function evaluations, such as the Functional Activity Questionnaire and Hamilton Depression Scale, were also carried out. The results were satisfactory, and the patient showed no signs of anxiety or depression.

\section{Discussion}

\section{Prehospital treatment}

Based on the outcomes of a prospective study, all GWH patients should initially receive aggressive resuscitation [6]. Patients with stable vital signs should be examined by CT. If the patient's GCS score after resuscitation is 3 to 5 and no operable hematomas are present, then no further therapy should be offered [2,6]. All patients with a GCS score greater than 5 should receive aggressive surgical therapy $[2,6]$. However, some recent retrospective studies have shown that GCS score at admission and the status of pupils and hemodynamics seem to be the most significant predictors of outcome in penetrating 

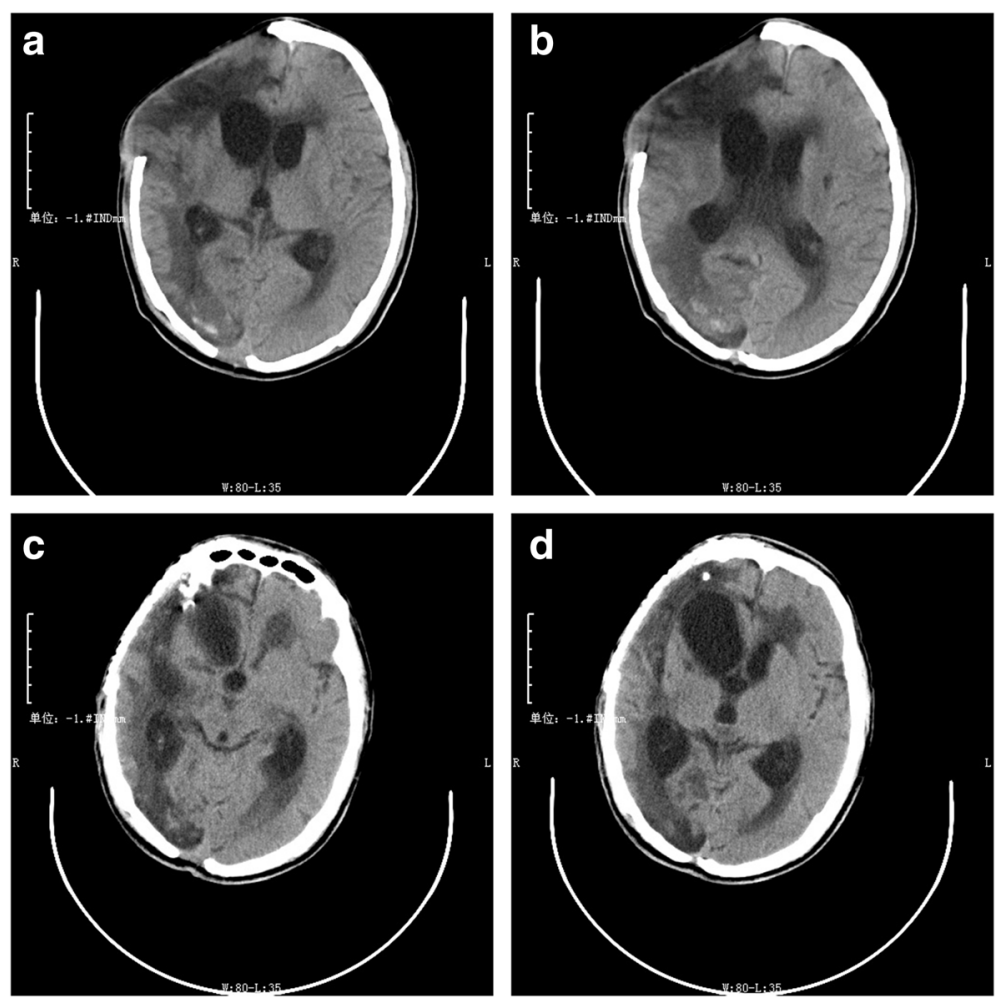

Fig. 3 Two months after discharge, a head computed tomography (CT) scan a and $\mathbf{b}$ revealed hydrocephalus. $\mathbf{c}$ and $\mathbf{d}$ show the head CT scan of the patient 1 month after the repair of the skull defect

GWH. CT scans, bi- or multilobar injury, and intraventricular hemorrhage were correlated with poor outcomes. Patients with a GCS score > 8, normal pupil reaction, and single-lobe brain injury may benefit from early aggressive management [7]. After undergoing a quick primary survey, all GWH victims with a GCS score $<9$ should be intubated, oxygenated, and ventilated. Systolic blood pressure should be maintained above $90 \mathrm{mmHg}$. After secondary survey and resuscitation, the patient should undergo a CT scan of the head $[1,7,8]$. In our case, although our patient could breathe when the emergency physician arrived at the scene, they still intubated him in time, which also won us valuable time for the subsequent emergency treatment. Grahm et al. showed that preventing secondary injuries from hypoxia and hypotension by field resuscitation improved patient outcomes [6]. Although Kaufman et al. did not specify whether the GCS score was evaluated before or after resuscitation, a few patients with GCS scores of 3 to 5 clearly have potential for a reasonable recovery. Using the GCS score at admission to categorize the patients' extent of injury and then to predict the outcome is only valid if the patient's best score is not obscured by other conditions, such as hypoxia, hypotension, or operable hematomas. Otherwise, it is difficult to make an accurate prognosis. In addition, GCS scores obtained after resuscitation eliminate the secondary causes of a decreased level of consciousness and accurately predict the extent of the initial injury and the patient's outcome [6]. In a 5-year retrospective review of 132 civilian patients with craniocerebral gunshot wounds, increasing survival was associated with aggressive resuscitation in all patients and resuscitation with blood products and hyperosmolar fluids were independently associated with survival. A GCS score of 3-5 and bihemispheric injury should not prevent early resuscitation, but a decision for expectant supportive care should be made when the patient has been stabilized and then reassessed, as some may improve. It is therefore the post-resuscitation GCS score that should be used for decision-making [4]. Acute traumatic coagulopathy (ATC) may develop in patients with isolated head injury (which includes GWH) and in the setting of multiple injuries with major blood loss and shock $[9,10]$. This latter scenario includes GWH. The diagnosis of ATC should be predicted rapidly before admission, and treatment should be prepared as soon as possible. Massive transfusion protocols have been developed in many trauma centers; replacement of blood and clotting components should be prepared at admission [11]. However, the optimal ratio of various plasma substitutes and blood products is uncertain and remains under investigation [12]. 
In summary, the prehospital treatment of GWH should include early aggressive resuscitation, correction of hypotension and hypoxia, maintenance of persistent bleeding, early intervention of ATC with emergency physician experience, and an urgent CT scan.

\section{Imaging studies}

Neurosurgeons all over the world agree that patients with brain injury should be sent to the imaging center for head CT scans as soon as they arrive at the hospital. Plain radiographs of the head can be helpful in assessing the bullet trajectory, the presence of large foreign bodies, and the presence of intracranial air. However, when CT scanning is available, plain radiographs are not essential and are not recommended as routine [13]. No imaging technique is faster and more accurate than CT. It has almost no contraindications, except for pregnant women. A CT scan of the head defines the bullet's trajectory, entry and exit sites, extent of intracranial fragments and proximity to major blood vessels and the ventricles, and pressure on the ambient cistern. In addition, a CT scan of the head will determine the need for surgery and define the strategy for surgical treatment. It is the recommended imaging modality with 5 -mm-thick continuous slices along the Reid line from the vertex to the foramen magnum for evaluating cranial trauma [14]. Patients who are found to have risk factors on CT scans, including intracerebral hematomas, orbital and facial craniocerebral injury, and patients with projectiles penetrating two or more ventricles, anterior circulation, and trajectories close to vertebrobasilar vessels, cavernous sinus, the dural venous sinuses, and the Sylvian fissure should undergo CT angiography (CTA), and if necessary, routine digital subtraction angiography, to rule out traumatic intracranial aneurysms [13, 15]. In our case, because of the emergency situation at the time, our patient was transferred to the operating room without CTA imaging after admission, but coincidentally, we found a middle cerebral bifurcation aneurysm when exploring the lateral fissure and then clipped it (Fig. 4). In the absence of CTA imaging, the evacuation of hematoma will be very passive for aneurysms found suddenly, which taught us a lesson. Fortunately, the aneurysms were not ruptured, so we clipped it safely. Obviously, this aneurysm had nothing to do with this injury. We speculate that this is not a traumatic aneurysm (TA), but an unruptured aneurysm. Fortunately, both bullets avoided this aneurysm. We suggest that, if time permits, head CTA should be performed in all patients regardless of whether such patients have a high risk of vascular injuries of the brain. It can not only help assess the vascular injury but also exclude vascular abnormalities of the patients themselves, which will play a key role in the final design of the operation.

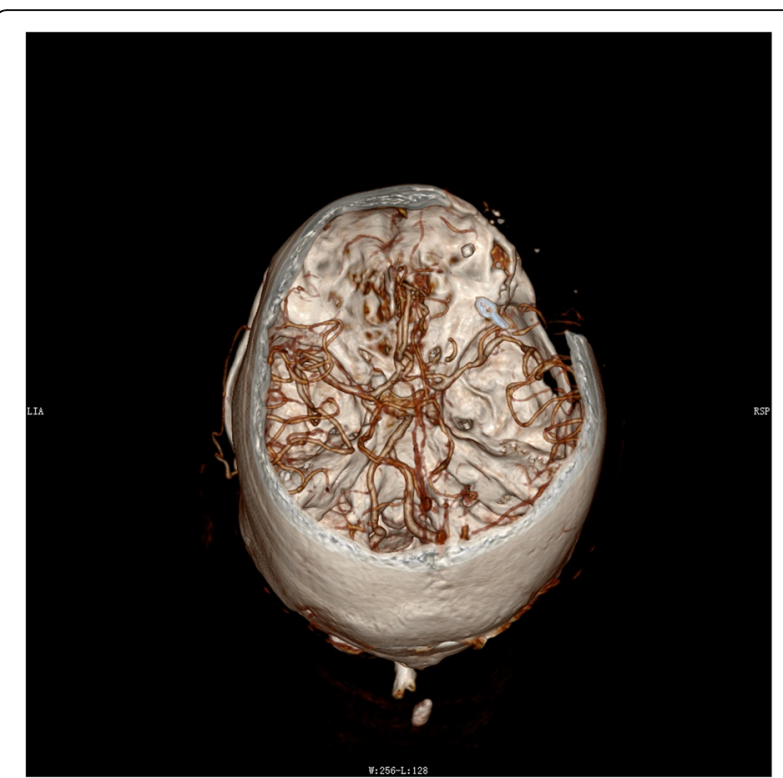

Fig. 4 In this three-dimensional computed tomography image, the arrow demonstrates the aneurysm clip at M3 of the right middle cerebral artery. This is an unruptured aneurysm that we found by accident during the first operation. We clipped the aneurysm while exploring the deep foreign body

Magnetic resonance imaging (MRI) studies are generally not recommended due to the uncertainty of bullet compositions. Moreover, in such an emergency, it is impractical to implement imaging modalities that are timeconsuming to obtain [13].

\section{Surgical management}

There is controversy regarding surgical management in patients with GWH. Most of the current treatment is based on data derived from retrospective observational military and civilian studies.

Minor gunshot injuries to the brain with nonpenetrating wounds, such as tangential ricocheting wounds, may only require local debridement, closure, and antibiotics. More severe focal injuries with hemorrhage and fragments without a mass effect may also require local exploration via a small craniotomy. Tubular and penetrating wounds are still great challenges for neurosurgeons. Severe penetrating injuries will require extensive surgery, even if a decision is made to operate. This may include debridement, evacuation of hematomas, decompressive craniectomy, dural repair, and stereotaxic technique.

Recent evidence indicates that after satisfactory primary debridement, the risk of deep intracranial infections decreases sharply. In such circumstances, there is no need for secondary debridement. Long-term followup of such patients from the Vietnam, Iran-Iraq, and Israel-Lebanon Wars indicates that without complicating 
risk factors such as cerebrospinal fluid (CSF) leakage, the chance of intracranial infection does not increase [16]. When intractable intracranial hypertension ( $\mathrm{ICH})$ or malignant brain swelling is found at the time of a CT scan or surgical exploration, decompressive craniectomy could be life-saving. Experience during Operation Iraqi Freedom has indicated that decompressive craniectomy can offer an invaluable surgical technique for controlling intracranial pressure (ICP) or impending brainstem compression [17-21]. Decompressive craniectomy has been used in civilian GWH and seems to be of value when there is extensive hemispheric swelling that is not responsive to maximum medical management [21].

In several studies, patients underwent debridement and decompressive craniectomy. Kaufman et al. [8] reported 20 survivors and 8 non-survivors who had major debridement and decompressive craniectomy. In the study by Grahm et al. [6], 43\% of patients underwent decompressive craniectomy specifically for debridement. Dosoglu et al. [6] reported 47 patients who underwent surgery, which included debridement and decompressive craniectomy. The concern in performing concurrent debridement and decompressive craniectomy is the potential development of cerebral abscesses [6, 22, 23]. Some authors have advocated a less aggressive cleaning procedure that preserves as much brain tissue as possible $[24,25]$, while others have suggested a more aggressive approach consisting of debridement of necrotic tissue, hematoma evacuation, removal of bone fragments, and foreign material as much as possible, establishing hemostasis, and dural closure [26-28]. Surgical intervention is not recommended for multilobular injuries and patients with a GCS score below 5 owing to a lack of survival benefit $[6,29]$. Grahm et al. do not recommend surgery in the absence of any significant hematoma or a bihemispheric or multilobar injury, or when GCS score is above 6-8 [30]. The great challenges and dilemmas for neurosurgeons treating severe GWH are whether to pursue surgery and survival of the patient at all costs or whether to pursue quality of survival, so as to provide the expected treatment for selected patients [2]. In many cases, the results may not be easy to predict, which results in a difficult choice on behalf of surgeons in the choice of their treatment, but also largely subject to the willingness of patients' families to trust the surgeon.

In our case, we decided to carry out the following operation plan: first, we quickly resected the temporal bone for decompression, then cut the dura mater to clear the wound along the trajectory and removed the temporal bullet and bone fragments. We did not aspirate much brain tissue, nor did we remove the occipital bullet fragment in the first operation. We aspirated the broken brain tissue and hematoma in the temporal lobe and maintained hemostasis, and at the same time, we clipped an unruptured aneurysm. This decision was dictated by several factors. The patient had a cerebral hernia at the time of admission (Fig. 1). The first problem to be solved is to relieve the compression of brain tissue. Decompressive craniectomy through the extended pterional approach can not only solve the problem of brain tissue compression but also remove the temporal bullet fragments and necrotic brain tissue. The reason why we did not remove the occipital bullet fragment at first is that the projectile trajectory in the occipital region was not clear and the extended pterional approach could not simultaneously remove the bullet fragment in the occipital lobe (Fig. 2). If the occipital bullet fragment was to be removed through a keyhole approach, we would have had to change the patient's supine position to a lateral decubitus or prone position after the temporal surgery. This is a dramatic change in position, and it cannot guarantee the stability of the vital signs after the first surgery. Moreover, the occipital bullet fragment did not endanger life temporarily because it had no spaceoccupying effect. Finally, an unruptured aneurysm was found during the first operation. For the sake of caution, we decided to review CTA after the operation to determine the cerebrovascular condition. Therefore, we chose not to remove the occipital foreign body for the time being. After the patient's vital signs were stable and CTA examination confirmed that there was no other vital vascular injury, the occipital bullet fragment was removed.

\section{Clinical management}

$\mathrm{ICH}$ is a major prognostic predictor in patients with penetrating head trauma, with higher values associated with worse outcomes. ICH is the primary cause of mortality in patients with head trauma, and is a known contributor to secondary brain injury [31]. However, the need for ICP monitoring is not as well defined in the postoperative management of patients with civilian GWH in the management and prognosis of penetrating brain injury [3, 32, 33]. Commonly used methods for ICP correction are the infusion of hypertonic saline and mannitol, short-term hyperventilation, CSF drainage, barbiturates and paralytics, and finally decompressive craniectomy. Correction of ICP should be started at ICP values higher than the threshold of $20 \mathrm{mmHg}$ registered for $5 \mathrm{~min}$ and longer.

Hyperventilation can be an efficient method for correcting $\mathrm{ICH}$ caused by cerebral hyperemia. When using hyperventilation, one should monitor whether oxygen supply to the brain is sufficient by measuring blood oxygen saturation in the jugular vein. Jugular venous oxygen saturation $\left(\mathrm{SvjO}_{2}\right)$ indices lying within $55-75 \%$ are considered normal, provided that oxygenation of arterial blood is sufficient. The normal brain tissue oxygen $\left(\mathrm{PbrO}_{2}\right)$ is $25-35 \mathrm{mmHg}$ with arterial blood pressure at 
80-100 mmHg. The partial pressure of $\mathrm{CO}_{2}\left(\mathrm{PaCO}_{2}\right)$ needs to be maintained at $36-40 \mathrm{mmHg}$. Mean blood pressure should be maintained above $90 \mathrm{mmHg}$ during the entire duration of intensive care. However, preventative hyperventilation $\left(\mathrm{PaCO}_{2}<35 \mathrm{mmHg}\right)$ within the first $24 \mathrm{~h}$ has been shown to carry a risk of worsening cerebral perfusion by decreasing cerebral perfusion pressure [31].

Short-term hyperventilation is permitted in the case of abrupt worsening of neurological status or for persistently raised ICP despite the use of sedatives, muscle relaxants, hyperosmolar solutions, or CSF drainage [34, 35]. In our case, hyperventilation was a temporary measure for reducing increased ICP. Our patient underwent non-invasive ICP monitoring since the first operation and returned to the intensive care unit. In the next $48 \mathrm{~h}$, he was administered continuous low-concentration oxygen therapy, and his GCS score reached 10 on the second day after surgery.

Civilian GWH are open, contaminated wounds that violate the scalp, skull, dura, and brain parenchyma. Devitalized brain tissue and retained bone fragments are suitable media for bacterial growth. Most contaminating organisms are those of skin flora, primarily Staphylococcus epidermidis [36, 37]. Patients with unknown immunization status and a contaminated wound to the head should receive a tetanus toxoid-containing vaccine intramuscularly and $250 \mathrm{U}$ of human immunoglobulin against tetanus at a different site than the tetanus toxoid [38]. Although not supported by any prospective randomized controlled study, the use of prophylactic broadspectrum antibiotics is appropriate for patients with penetrating brain injuries (PBI) since these wounds are considered to be contaminated [39]. According to the current US military guidelines, patients should receive cefazolin for 5-7 days [40]. Helling et al. stated that antibiotics, usually cephalosporins for blood-brain barrier penetration, were routinely administered to all patients, and no instances of postoperative brain abscesses have been reported [41, 42].

Seizure is another common complication seen in patients with traumatic brain injury, with an incidence ranging from 1.1-53\%. Posttraumatic seizures are classified as early if the first seizure occurs within 7 days of the trauma, or late, if the first seizure develops 1 week after trauma [43-45]. Seizures were most often generalized with or without focal onset. Although no prospective study has indicated the efficacy of prophylactic antiseizure medications after a PBI, it has been recommended that patients be covered for about the first week after injury with a medication such as phenytoin or carbamazepine [46, 47]. Anticonvulsants such as phenytoin and carbamazepine are recommended for patients in the acute phase of severe traumatic brain injury with a high risk of seizure development. Results of class I studies show that preventative therapy with phenytoin, carbamazepine, phenobarbital, or valproate is not effective against late seizure onset in patients with traumatic brain injury [34].

\section{Complications}

The implanted material along with necrotic brain and bone fragments are usually at the entrance of the incurred brain wound, and if the wound is not welldebrided, it can act as a site of infection [39]. Among the complications of GWH are CSF leaks or fistulas, which have been reported to occur in $0.63-8.9 \%$ of patients. They are more frequent in patients with ventricular involvement and incomplete dural and scalp closure, and the chance of infection was increased 20-fold in patients with CSF fistulas. The rate of Gram-negative infection was also 3 times higher in patients with CSF fistulas than in patients without CSF fistulas. Patients whose wounds are complicated by fistulas have more extensive wounds. If the ventricle is penetrated, CSF can leak into the missile tract into the subdural space and can leak through suture lines of the dural graft and skin. Aarabi recommended repeated lumbar puncture, spinal thecal drainage, or even insertion of a shunt in selected patients until the scalp suture line was healed completely [48]. In addition to the usual complications produced by penetrating head injuries, late-onset intracerebral hemorrhage caused by rupture of TAs has been a major cause of death. Early diagnosis of these vascular insults with prompt attention to a proper diagnostic and therapeutic protocol may prevent such potentially fatal events. The following are high risks of developing into TAs: passage of missile or bone fragments through areas of crowded vasculature and/or through the skull base (through Reil's triangle or from one hemisphere to the other); a remarkable amount of hematoma within the entrance pathway that is visible on the predebridement CT scan; multiple shells or bone fragments scattered in paths that branch into various directions. The appropriate time for performing angiography to locate a TA is during the first 10 days after injury [49].

Angiography should be performed as soon as possible after encountering high-risk patients. Surgery to treat TAs is a difficult challenge because they usually do not have a neck suitable for clipping. TAs should either be excluded from the main circulation by trapping or they should be coagulated. In cases where the harboring vessel is a major artery, coating the aneurysm with muslin or fibrin glue or excision of the TA after extracranialintracranial bypass might be the preferred method of surgery $[50,51]$. In wars and in younger patients, Hunterian ligation of extracranial vessels harboring expansile and/or symptomatic TAs or arteriovenous fistulas is a 
very effective therapy and will usually not compromise cerebral blood perfusion [50].

\section{Conclusion}

To summarize, GWH represent a high-mortality emergency for trauma surgeons. Aggressive management is essential to improve prognosis and patient outcomes. This case describes a patient who successfully recovered after two gunshots to the head. He underwent aggressive debridement and medical prophylaxis against seizures and infections. Given the severity of his injuries, he had a remarkable outcome and returned to his family and activities of daily living following a short hospital course.

\begin{abstract}
Abbreviations
GWH: Gunshot wounds to the head; GCS: Glasgow Coma Scale; CT: Computed tomography; ATC: Acute traumatic coagulopathy; CTA: CT angiography; MRI: Magnetic resonance imaging; CSF: Cerebrospinal fluid; ICH: Intracranial hypertension; ICP: Intracranial pressure; TAs: Traumatic aneurysms
\end{abstract}

\section{Acknowledgements}

We would like to thank Editage (www.editage.cn) for English language editing.

\section{Authors' contributions}

$\mathrm{HQ}$ conducted the literature review and manuscript writing. The authors read and approved the final manuscript.

\section{Funding}

This research did not receive any specific grant from funding agencies in the public, commercial, or not-for-profit sectors.

\section{Availability of data and materials}

The data supporting the conclusions of this article are included within the article.

\section{Ethics approval and consent to participate}

Not applicable.

\section{Consent for publication}

Written informed consent for publication was obtained from the patient and his legal guardians.

\section{Competing interests}

The authors declare that they have no competing interests.

\section{Author details}

'Qinghai University, No. 251 Ningda Road, Xining 810016, Qinghai Province, China. ${ }^{2}$ The Affiliated Hospital of Qinghai University, No. 29 Tongren Road, Xining 810000, Qinghai Province, China.

Received: 18 August 2020 Accepted: 15 December 2020

Published online: 03 February 2021

\section{References}

1. Ambrosi PB, Valença MM, Azevedo-Filho H. Prognostic factors in civilian gunshot wounds to the head: a series of 110 surgical patients and brief literature review. Neurosurg Rev. 2012;35(3):429-36. https://doi.org/10.1007/ s10143-012-0377-2.

2. Rosenfeld JV, Bell RS, Armonda R. Current concepts in penetrating and blast injury to the central nervous system. World J Surg. 2015;39(6):1352-62. https://doi.org/10.1007/s00268-014-2874-7.

3. Aarabi B, Tofighi B, Kufera JA, et al. Predictors of outcome in civilian gunshot wounds to the head: clinical article. J Neurosurg. 2014;120(5):113846. https://doi.org/10.3171/2014.1.JNS131869.
4. Joseph B, Aziz H, Pandit V, et al. Improving survival rates after civilian gunshot wounds to the brain. J Am Coll Surg. 2014;218(1):58-65. https://doi. org/10.1016/j.jamcollsurg.2013.08.018.

5. Gressot LV, Chamoun RB, Patel AJ, et al. Predictors of outcome in civilians with gunshot wounds to the head upon presentation: clinical article. J Neurosurg. 2014;121(3):645-52. https://doi.org/10.3171/2014.5.JNS131872.

6. Grahm TW, Williams FC, Harrington T, Spetzler RF. Civilian gunshot wounds to the head: a prospective study. Neurosurgery. 1990;27(5).

7. Hofbauer M, Kdolsky R, Figl M, et al. Predictive factors influencing the outcome after gunshot injuries to the head-a retrospective cohort study. J Trauma Inj Infect Crit Care. 2010;69(4):770-5. https://doi.org/10.1097/TA. Ob013e3181c81d7d.

8. Kaufman HH, Loyola WP, Makela ME, et al. Civilian gunshot wounds: the limits of salvageability. Acta Neurochir (Wien). 1983;67(1-2):115-25. https:// doi.org/10.1007/BF01401671.

9. McCully S, Schreiber M. Traumatic brain injury and its effect on coagulopathy. Semin Thromb Hemost. 2013;39(08):896-901. https:/doi.org/ 10.1055/s-0033-1357484.

10. Halpern CH, Reilly PM, Turtz AR, Stein SC. Traumatic coagulopathy: the effect of brain injury. J Neurotrauma. 2008;25(8):997-1001. https://doi.org/10 1089/neu.2008.0548.

11. Mitra B, O'Reilly G, Cameron PA, Zatta A, Gruen RL. Effectiveness of massive transfusion protocols on mortality in trauma: a systematic review and metaanalysis: effectiveness of MTP on mortality. ANZ J Surg. 2013;83(12):918-23. https://doi.org/10.1111/ans.12417.

12. Baraniuk S, Tilley BC, del Junco DJ, et al. Pragmatic randomized optimal platelet and plasma ratios (PROPPR) trial: design, rationale and implementation. Injury. 2014;45(9):1287-95. https://doi.org/10.1016/j.injury 2014.06.001

13. \&Na; Neuroimaging in the management of penetrating brain injury: J Trauma Inj Infect Crit Care. 2001; 51(Supplement):S7-S11. doi: 10.1097/ 00005373-200108001-00004.

14. Düz B, Gönül E. Silah Yaralanmalar na Bal. Turk Neurosurg. 2009;19(3):8.

15. Bodanapally UK, Shanmuganathan K, Boscak AR, et al. Vascular complications of penetrating brain injury: comparison of helical CT angiography and conventional angiography: Clinical article. J Neurosurg. 2014;121(5):1275-83. https://doi.org/10.3171/2014.7.JNS132688.

16. Amirjamshidi A, Abbassioun $\mathrm{K}$, Rahmat H. Minimal debridement or simple wound closure as the only surgical treatment in war victims with lowvelocity penetrating head injuries. Surg Neurol. 2003;60(2):105-10. https:// doi.org/10.1016/S0090-3019(03)00358-6.

17. Okie S. Traumatic Brain Injury in the War Zone. N Engl J Med. 2005:5.

18. Bell RS, Mossop CM, Dirks MS, et al. Early decompressive craniectomy for severe penetrating and closed head injury during wartime. Neurosurg Focus. 2010;28(5):E1. https://doi.org/10.3171/2010.2.FOCUS1022.

19. Rosenfeld JV, Cooper DJ. What is the role for decompressive craniectomy in severe traumatic brain injury? Re: Decompressive craniectomy: Surgical control of intracranial hypertension may improve outcome. Injury. 2010; 41(9):899-900. https://doi.org/10.1016/j.injury.2010.06.010.

20. Eberle BM, Schnüriger B, Inaba K, Peter Gruen J, Demetriades D, Belzberg H. Decompressive craniectomy: surgical control of traumatic intracranial hypertension may improve outcome. Injury. 2010;41(9):894-8. https://doi. org/10.1016/j.injury.2010.02.023.

21. Sahuquillo J, Dennis JA. Decompressive craniectomy for the treatment of high intracranial pressure in closed traumatic brain injury. Cochrane Injuries Group, ed. Cochrane Database Syst Rev. Published online December 31, 2019. doi:10.1002/14651858.CD003983.pub3.

22. Maragkos GA, Papavassiliou E, Stippler M, Filippidis AS. Civilian gunshot wounds to the head: prognostic factors affecting mortality: meta-analysis of 1774 patients. $J$ Neurotrauma. 2018;35(22):2605-14. https:/doi.org/10.1089/neu.2018.5682.

23. Kaufman HH, Makela ME, Lee F, Haid RW Jr, Gildenberg PL. Gunshot wounds to the head: a perspective. Neurosurgery. 1986;18(6):689-95.

24. Kubal WS. Updated imaging of traumatic brain injury. Radiol Clin North Am. 2012;50(1):15-41. https://doi.org/10.1016/j.rcl.2011.08.010.

25. Clark WC. Analysis of 76 civilian craniocerebral gunshot wounds. Neurosurg. 1986;65:6.

26. Aarabi B. Surgical outcome in 435 patients who sustained missile head wounds during the Iran-Iraq war. Neurosurgery. 1990;27(5):692-5.

27. Rish BL, Dillon JD, Caveness WF, Mohr JP, Kistler JP, Weiss GH. Evolution of craniotomy as a debridement technique for penetrating craniocerebral injuries. J Neurosurg. 1980;53(6):772-5. https://doi.org/10.3171/jns.1980.53.6.0772. 
28. Gurdjian ES. The treatment of penetrating wounds of the brain sustained in warfare: a historical review. J Neurosurg. 1974;39:11.

29. Shoung HM, Sichez JP, Pertuiset B. The early prognosis of craniocerebral gunshot wounds in civilian practice as an aid to the choice of treatment: series of 56 cases studied by the computerized tomography. Acta Neurochir (Wien). 1985;74(1-2):27-30. https://doi.org/10.1007/BF01413272.

30. Nagib MG, Rockswold GL, Sherman RS, Lagaard MW. Civilian gunshot wounds to the brain: prognosis and management. Neurosurgery. 1986;18(5): 533-7.

31. Abdelmalik PA, Draghic N, Ling GSF. Management of moderate and severe traumatic brain injury. Transfusion (Paris). 2019;59(\$2):1529-38. https://doi. org/10.1111/trf.15171.

32. Kasper E, Lin D, Siracuse J, Lam F, Thomas A. "Time is brain" the Gifford factor - or: why do some civilian gunshot wounds to the head do unexpectedly well? A case series with outcomes analysis and a management guide. Surg Neurol Int. 2012;3(1): 98. doi:10.4103/2152-7806. 100187

33. Fathalla $\mathrm{H}$, Ashry A, El-Fiki A. Managing military penetrating brain injuries in the war zone: lessons learned. Neurosurg Focus. 2018;45(6):E6. https://doi. org/10.3171/2018.8.FOCUS18371.

34. Potapov AA, Krylov W, Gavrilov AG, et al. Guidelines for the diagnosis and treatment of severe traumatic brain injury. Part 2. Intensive care and neuromonitoring. Vopr Neirokhirurgii Im NN Burdenko. 2016; 80(1): 98. doi: 10.17116/neiro201680198-106.

35. Spaite DW, Bobrow BJ, Keim SM, et al. Association of statewide implementation of the prehospital traumatic brain injury treatment guidelines with patient survival following traumatic brain injury: the excellence in prehospital injury care (EPIC) Study. JAMA Surg. 2019;154(7): e191152. https://doi.org/10.1001/jamasurg.2019.1152.

36. Carey ME, Young HF, Mathis JL. The bacterial contamination of indriven bone fragments associated with craniocerebral missile wounds in Vietnam. Mil Med. 1970;135(12):1161-5. https://doi.org/10.1093/milmed/135.12.1161

37. Aarabi B, Alibaii E, Taghipur M, Kamgarpur A. Comparative study of functional recovery for surgically explored and conservatively managed spinal cord missile injuries. Neurosurgery. 1996;39(6):1133-40.

38. Havers FP, Moro PL, Hunter P, Hariri S, Bernstein H. Use of tetanus toxoid, reduced diphtheria toxoid, and acellular pertussis vaccines: updated recommendations of the advisory committee on immunization practices United States, 2019. MMWR Morb Mortal Wkly Rep. 2020; 69(3):77-83. doi:10. 15585/mmwr.mm6903a5.

39. Bizhan A, Mossop C, Aarabi JA. Surgical management of civilian gunshot wounds to the head. Handb Clin Neurol. 2015;127:181-93. https://doi.org/10. 1016/B978-0-444-52892-6.00012-X.

40. Hazama A, Ripa V, Kwon C-S, Abouelleil M, Hall W, Chin L. Full recovery after a bihemispheric gunshot wound to the head: case report, clinical management, and literature review. World Neurosurg. 2018;117:309-14. https://doi.org/10.1016/j.wneu.2018.06.132

41. Helling TS. The role of early surgical intervention in civilian gunshot wounds to the head. J Trauma. 1992;32(3):398-400.

42. Martins RS, Siqueira MG, Santos MTS, Zanon-Collange N, Moraes OJS Prognostic factors and treatment of penetrating gunshot wounds to the head. Surg Neurol. 2003;60(2):98-104. https://doi.org/10.1016/S00903019(03)00302-1.

43. Klein P, Herr D, Pearl PL, Natale J, Levine Z, Nogay C, Sandoval F, Trzcinski S, Atabaki SM, Tsuchida T, van den Anker J, Soldin SJ, He J, McCarter R. Results of phase 2 safety and feasibility study of treatment with levetiracetam for prevention of posttraumatic epilepsy. Arch Neurol. 2012;69(10):1290-5. https://doi.org/10.1001/archneurol.2012.445.

44. Salazar AM, Jabbari B, Vance SC, Grafman J, Amin D, Dillon JD. Epilepsy after penetrating head injury. I. Clinical correlates: a report of the Vietnam Head Injury Study. Neurology. 1985;35(10):1406-14. https://doi.org/10.1212/wnl.35. 10.1406 .

45. Pearl PL, McCarter R, McGavin CL, et al. Results of phase II levetiracetam trial following acute head injury in children at risk for posttraumatic epilepsy. Epilepsia. 2013;54(9):e135-7. https://doi.org/10.1111/epi.12326.

46. Temkin NR, Dikmen SS, Wilensky AJ, Keihm J, Chabal S, Winn HR. A randomized, double-blind study of phenytoin for the prevention of posttraumatic seizures. N Engl J Med. 1990;323(8):497-502. https://doi.org/ 10.1056/NEJM199008233230801.
47. Temkin NR. Risk factors for posttraumatic seizures in adults: risk factors for posttraumatic seizures. Epilepsia. 2003:44:18-20. https://doi.org/10.1046/j. 1528-1157.44.s10.6.x

48. Aarabi B. Causes of infections in penetrating head wounds in the Iran-Iraq war. Neurosurgery. 1989;25(6):923-6.

49. Amirjamshidi A, Rahmat H, Abbassioun K. Traumatic aneurysms and arteriovenous fistulas of intracranial vessels associated with penetrating head injuries occurring during war: principles and pitfalls in diagnosis and management: a survey of 31 cases and review of the literature. J Neurosurg. 1996;84(5):769-80. https://doi.org/10.3171/jns.1996.84.5.0769.

50. Amirjamshidi A, Abbassioun K, Rahmat H. Traumatic aneurysms and arteriovenous fistulas of the extracranial vessels in war injuries. Surg Neurol. 2000;53(2):136-45. https://doi.org/10.1016/S0090-3019(99)00181-0.

51. He $Y$, Wang $L$, Ou $Y$, et al. Surgical treatment of traumatic distal anterior cerebral artery aneurysm: a report of nine cases from a single centre. Acta Neurochir (Wien). 2020;162(3):523-9. https://doi.org/10.1007/s00701-01904121-x.

\section{Ready to submit your research? Choose BMC and benefit from:}

- fast, convenient online submission

- thorough peer review by experienced researchers in your field

- rapid publication on acceptance

- support for research data, including large and complex data types

- gold Open Access which fosters wider collaboration and increased citations

- maximum visibility for your research: over $100 \mathrm{M}$ website views per year

At BMC, research is always in progress.

Learn more biomedcentral.com/submissions 